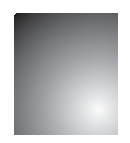

\title{
Inovação de Produtos e Processos sob a Perspectiva da Gestão Ambiental
}

\author{
Products and Processes Innovation from the Perspective of \\ Environmental Management
}

Vanessa Theis

Doutoranda do Programa de Pós Graduação em Qualidade Ambiental na Universidade Feevale. Novo Hamburgo, RG. Brasil. E-mail: nessa.theis@gmail.com

\section{Dusan Schreiber}

Doutor em Administração pela Universidade Federal do Rio Grande do Sul. Professor e pesquisador do Programa de Pós Graduação em Qualidade Ambiental e Coordenador do Mestrado em Indústria Criativa. Universidade Feevale. Novo Hamburgo, RG. Brasil.

E-mail: dusan@feevale.br

\section{Resumo}

Considerando o atual cenário de globalização da economia, no qual a dinâmica do mercado determina a velocidade da mudança nos modelos de negócios, os aspectos ambientais podem contribuir para a concepção de inovações tecnológicas. Diante dessa percepção, o objetivo geral desta pesquisa é investigar como as organizações industriais do setor metalmecânico, localizadas na região do Vale do Rio dos Sinos, conciliam as atividades de inovação de produtos e processos, com os princípios estruturantes (dimensões social, ambiental e econômica) da gestão ambiental. Os dados foram coletados por meio de uma pesquisa survey, realizada com gestores de 159 empresas. As evidências facultaram a constatação de que as inovações obtidas tendem a ser adequações aos dispositivos legais que exigem a mitigação dos impactos ambientais no processo de produção, em especial na redução da poluição e na utilização de recursos menos tóxicos, o que não gera estímulo suficiente para o desenvolvimento de novos produtos.

Palavras-chave: Gestão Ambiental. Inovação. Setor Metalmecânico.

\section{Abstract}

Considering the present scenario of globalization of the economy, the dynamics of the market determines the speed of change in business models, environmental aspects can contribute to the design of technological innovations. Given this perception, the general objective of this research was to investigate how industrial organizations in the metal-mechanic sector, located in the Vale do Rio dos Sinos region, reconcile the product innovation activities and processes, with the structuring principles of environmental management. This economic segment is characterized as one that has the highest rates of innovation and greater investment in research and development. Data were collected through a survey research with managers of 159 companies of the analysis unit. Evidence collected provided the realization that innovations tend to be adjustments made to the legal provisions that require the mitigation of environmental impacts in the production process, especially in reducing pollution and using less toxic assets, which does not generate sufficient stimulus to the development of new products.

Keywords: Environmental Management. Innovation. Metal-mechanic Industry. 


\section{INTRODUÇÃo}

Geralmente, o posicionamento estratégico das organizações diante dos desafios mercadológicos, relacionava-se a alterações na qualidade e quantidade de insumos alocados em um determinado produto ou processo produtivo, a fim de reduzir custos para tornarem-se competitivas. Entretanto, neste novo cenário, as empresas precisam desenvolver produtos que atendam as necessidades e expectativas de consumidores, além de satisfazer as exigências dos stakeholders por ações de atuação empresarial que reduzam o impacto sobre o meio ambiente (JABBOUR, 2007).

Dessa forma, à medida que os problemas ambientais ficaram mais evidentes, exigindo um novo posicionamento dos executivos, destaca-se a concepção de uma nova responsabilidade social empresarial, que aponta a gestão ambiental como reflexo do poder ampliado das empresas de tornarem-se aliadas do desenvolvimento sustentável. Nesse sentido, a ação conjunta de diferentes profissionais possibilita a realização de novos estudos, buscando despertar reflexões e atitudes, além de orientar o reposicionamento estratégico voltado para a gestão ambiental e o desenvolvimento de produtos sustentáveis (MORT, 2001; MANZINI; VEZZOLI, 2002).

Dados da Associação Nacional de Pesquisa, Desenvolvimento e Engenharia das Empresas Inovadoras (ANPEI, 2011), entidade que realiza pesquisas com o objetivo de caracterizar o cenário brasileiro da inovação, revelam que as empresas brasileiras, mantém um padrão de inovação baseado no acesso ao conhecimento tecnológico, por meio da incorporação de máquinas e equipamentos. Além disto, o estudo ressalta que as estratégias tecnológicas, na maioria dos casos se limitam a processos de difusão de tecnologias conhecidas, voltadas para projetos que reduzem custos e aumentem a eficiência produtiva, associadas, principalmente às inovações de processos.

No contexto das indústrias do segmento metalmecânico, o estudo da ANPEI (2011) identificou que esta atividade industrial caracteriza-se com uma das que apresentam as maiores taxas de inovação $e$ os maiores investimentos em P\&D. Consequentemente, são as atividades que mais empregam recursos humanos dedicados às atividades de P\&D. Além disso, o relatório sinaliza que esse segmento merece atenção especial dos agentes econômicos, devido ao seu potencial inovador e disseminador das melhores práticas para a indústria em geral.

Diante dessa percepção mercadológica, esta pesquisa objetiva investigar como as organizações industriais do setor metalmecânico, localizadas na região do Vale do Rio dos Sinos, conciliam as atividades de inovação de produtos e processos, com os princípios estruturantes (dimensões social, ambiental e econômica) da gestão ambiental. Cumpre destacar que a matriz econômica da região do Vale do Rio dos Sinos, é constituída por uma rede de organizações industriais complementares, que contam com clientes e fornecedores, formando um conjunto integrado e complexo.

A proposta do estudo se justifica pela relevância do segmento, tanto em nível regional como estadual, na geração de emprego e renda, bem como pela interface do contexto econômico e ambiental. Nessa perspectiva $e$ à luz de uma abordagem sistêmica, sugere-se averiguar qual o nível de aderência entre as práticas de gestão ambiental corporativa presente no processo de inovação organizacional, em especial ao de pesquisa e desenvolvimento de novos produtos.

\section{Gestão Ambiental}

Sanches (2000) apresenta algumas práticas ambientais que conduzem ao desempenho ambiental lucrativo e responsável. Incialmente, a organização deve atentar-se à saúde e segurança de seus colaboradores, consumidores e da comunidade. Além disto, modificar ou substituir os processos, produtos e serviços de modo a torná-los ambientalmente favoráveis, por meio de políticas que evitem o uso de recursos escassos, reduzir os materiais de embalagem, eliminação de produtos químicos e emissões tóxicas. Logo após, recuperar, por meio de reciclagem e reutilização, resíduos, produtos secundários e embalagens, tais como produtos químicos, papel, plástico, metal e água.

Nesse debate teórico, Dyllick et al. (2000), entendem que a gestão ambiental abrange todos os setores necessários ao planejamento, execução, revisão $e$ desenvolvimento de uma política ambiental da organização. Dessa forma, Beard e Rees (2000) observam que as equipes ambientais são utilizadas para fomentar a aprendizagem organizacional, gerar ideias, identificar 
conflitos e focar atenção em sua resolução, perseguindo sempre as melhores opções em termos de prática de gestão do meio ambiente.

Toms (2001) aponta que uma boa gestão ambiental melhora a reputação das empresas e permite a diferenciação de produtos. Segundo o autor, o aperfeiçoamento na gestão ambiental pouco tem acrescentado na melhoria da eficiência e da produtividade. O autor acredita que, os investidores estariam mais atentos ao potencial de redução dos riscos do que propriamente a possibilidade de aumento de lucratividade (TOMS, 2001). Nessa discussão, Nascimento (2001) entende que essa reação dos investidores indica que a introdução de produtos de menor impacto ambiental ou o aprimoramento dos já existentes tende a melhorar a reputação da empresa e, assim, capacitá-la a alcançar estratégias de diferenciação ambientalmente sustentáveis.

Souza (2002) realizou uma análise teórica, a fim de aprofundar as transformações ocorridas nas estratégias ambientais, os seus condicionantes e a forma como se diferenciam nas organizações. Constatou-se que as escolhas estratégicas que as empresas fazem, quanto a serem mais ou menos ativas ambientalmente, dependem, pelo menos em parte, da interpretação que os gestores fazem da questão ambiental, se como uma oportunidade ou um risco, um investimento ou um custo. O autor menciona a existência de uma inconsistência entre o que as empresas professam e planejam em termos ambientais, com o que elas efetivamente fazem.

Com relação à adoção de estratégias voltadas para produtos ou dirigidas para processos, Souza (2002) conclui que elas variam em função do ambiente em que a organização está inserida e do tipo de formação das estratégias, se emergente ou deliberada. As estratégias emergentes do setor de produção, por exemplo, tendem a ser direcionadas a processos, em função da natureza das atividades e dos problemas que este setor enfrenta. Quanto ao ambiente em que a organização está inserida, poder-se-ia supor que empresas concorrendo em mercados de commodities tendem a dirigir suas iniciativas ambientais para processos, a fim de melhorar a eficiência e reduzir custos. Por outro lado, empresas que competem em mercados de elevada diferenciação direcionam as ações ambientais para produtos.
Nesse sentido, Nielsen e Wenzel (2002) ressaltam que as decisões mais importantes concernentes às propriedades ambientais de um determinado produto, são tomadas nas primeiras fases do projeto. Dessa forma, melhorias ambientais significativas podem ser alcançadas considerando-se as propriedades ambientais como um parâmetro a ser aprimorado, juntamente com funcionalidade, ergonomia e custos de produção. Destarte, Manzini e Vezzoli (2002) afirmam que as companhias estão buscando aliar as vantagens econômicas com as ecológicas, por meio da aplicação de inovações tecnológicas que reduzam o impacto ambiental e assim desenvolver produtos sustentáveis.

A partir dessa transformação cultural, a gestão ambiental visa à concepção de ações proativas, envolvendo permanentemente toda a cadeia produtiva, bem como toda a organização, em ações corretivas, preventivas e antecipatórias mediante o risco de problemas ambientais. Portanto, o desenvolvimento de produtos sustentáveis passa a referir-se ao controle ambiental integrado às práticas e processos produtivos das organizações (ANDRADE; TACHIZAWA; CARVALHO, 2002).

Do mesmo modo, para Elefsiniotis e Warrham (2005), a gestão ambiental concerne à totalidade de ações organizacionais, de forma sistematizada para monitorar impactos ambientais de suas atividades $e$ gerenciar questões pertinentes à dimensão ambiental. Compete-lhe ainda, a tarefa de monitorar a legislação ambiental, interpretá-la, e agir, para que o processo produtivo gere impactos ambientais em patamares legalmente aceitos. Logo, o processo de desenvolvimento de produto passa a incorporar as questões ambientais de forma direta, uma vez que a gestão ambiental objetiva reduzir a poluição e o desperdício de inputs organizacionais (CAGNO; TRUCCO; TARDINI, 2005).

Todavia, mesmo diante do cenário otimista $e$ repleto de oportunidades explanado por diversos autores, Donaire (2007) evidenciou nas empresas brasileiras que a interiorização da questão ambiental é consequência, em um primeiro momento, de influências externas provenientes da legislação ambiental e das pressões exercidas pela comunidade nacional $e$ internacional. Além disso, as respostas das empresas ao grande número de normas legais e às críticas da sociedade faz com que predominem os métodos corretivos para a solução de problemas ambientais causados 
pelas atividades das empresas, buscando eliminar ou reduzir os impactos negativos gerados por sua atividade (DIAS, 2011).

Cabe mencionar o trabalho de Oliveira e Serra (2010), na obra desses autores, foi possível verificar os benefícios e as dificuldades da adoção de Sistemas de Gestão Ambiental em empresas industriais do Estado de São Paulo. Os autores concluíram que a adoção de Sistemas de Gestão Ambiental gera economias e, consequentemente maior competitividade, em função da modernização de projetos e processos, da redução do desperdício, da emissão de resíduos e do número de ocorrência e multas provenientes dos órgãos de fiscalização. Dentre as dificuldades na implantação $e$ gerenciamento de um sistema de gestão ambiental, os autores constataram que as empresas pesquisadas, $\mathrm{O}$ principal item que atrapalha é o aumento nos custos.

Para Grael e Oliveira (2010), o elemento mais importante na integração de sistemas de gestão ambiental e de qualidade é o compromisso da alta administração. Os autores sugerem que a alta administração deve estar em contato direto com todos os níveis hierárquicos, de forma a criar um vínculo permanente de cordialidade entre todos na empresa e gerar um ambiente de trabalho saudável para inspirar confiança e induzir a execução de processos com qualidade e consciência ambiental. Ao acompanhar a execução dos processos $e$ as ações de melhoria, fomenta-se o comportamento proativo e as sugestões de aprimoramento de produtos, processos e de elementos para aumento da integração dos sistemas por parte dos colaboradores.

Fonseca e Martins (2010) complementam que a incorporação da dimensão ambiental no contexto das estratégias organizacionais ocorreu em virtude dos múltiplos efeitos das crescentes mobilizações sociais e políticas. Barbieri (2011) corrobora que se não houvesse pressões da sociedade e medidas governamentais, não se observaria envolvimento das empresas em questões ambientais. Outra fonte de pressão, constatada por Barbieri (2011), advém do aumento da conscientização dos consumidores, sobre o uso de produtos e serviços ambientalmente saudáveis.

Sendo assim, constata-se que a tríade economia, ambiental e social passa a assumir lugar de destaque em um cenário competitivo e dinâmico, fazendo que a adoção de processos produtivos sustentáveis e a adequada gestão de resíduos e emissões passam a ser mais valorizados (BANKUTI; BANKUTI, 2011). Como resultado, constata-se que a expansão da consciência coletiva com relação ao meio ambiente exige um novo posicionamento dos executivos, fazendo com que as organizações empreendam soluções voltadas ao desenvolvimento sustentável e ao mesmo tempo à lucratividade do negócio principal (TACHIZAWA; ANDRADE, 2012), por meio do melhor gerenciamento de processos e lançamento de produtos amigáveis ambientalmente (SELLITTO et al., 2012).

Por fim, Arruda et al. (2014, p. 103) ratificam que "[...] a busca por novos arranjos de crescimento e desenvolvimento em consonância com melhor aproveitamento dos recursos naturais e minimização de impactos ambientais [...]", estruturou a gestão ambiental nas empresas. As organizações que decidem integrar a gestão ambiental a sua estratégia de negócio, cada decisão se torna uma oportunidade de criação de valor para impulsionar a inovação, conseguir o comprometimento dos colaboradores e da comunidade, além de construir uma cultura de alto desempenho. Por conseguinte, quando as formas existentes de produção não se mostrarem compatíveis com a preservação do meio ambiente, a inovação se torna importante ferramenta para a empresa em busca de alternativas.

\section{Gestão da Inovação}

Os conceitos sobre os ciclos econômicos, formulados pelo economista Schumpeter (1982), são relevantes na atual ciência econômica. De acordo como o autor, o que provoca a alteração no estado de equilíbrio econômico, avançando para um processo de expansão, é o surgimento de alguma inovação. Para ele, a abertura de novos mercados, a criação de novos bens e serviços, a descoberta de um novo método de produção ou de comercialização, o uso de novas tecnologias ou a alteração da estrutura do mercado vigente são indicadores de inovação (SCHUMPETER, 1982).

Schumpeter (1982) compreende o processo de inovação de forma muito capitalista, uma peculiaridade do seu tempo. Os fatores que orientam a sua visão de desenvolvimento capitalista são a inovação como a determinante e os empreendedores como agentes facilitadores deste processo. Desse pensamento surge a destruição criativa, em que a inovação é vista como 
a substituição de formas antigas por novas e os indivíduos fazem uso do processo de destruição criativa, pois são movidos pelo desejo do lucro extraordinário.

Contribuindo aos estudos do economista, Porter (1989) afirma que a evolução tecnológica é o fato mais relevante que pode modificar as regras da concorrência, exercendo um papel importante na criação de novos mercados. A introdução de uma inovação tecnológica permite a redução de custos ou a diferenciação e, talvez, ambas as estratégias. Nesse sentido, uma organização pode utilizar o desenvolvimento tecnológico de maneira que a favoreça. Assim, uma transformação tecnológica aumenta a vantagem competitiva, se resultar em custo mais baixo, ou, em diferenciação, se puder ser protegida de imitações.

Para Tidd e Bessant (2015), a inovação é orientada pela habilidade de fazer relações, de visualizar oportunidades e de tirar vantagem dessas oportunidades e de explorá-las. A capacidade de distinguir oportunidades e criar novas formas de explorá-las é indispensável ao processo de inovação e envolve possibilidades inteiramente novas, como a exploração de avanços tecnológicos totalmente radicais. Todavia a inovação não só requer a abertura de novos mercados, como exige a implementação de novas formas de servir àqueles já estabelecidos e maduros.

Diferente dos conceitos de inovação discutidos, como a abertura de novos mercados ou a alteração da estrutura dos negócios já existentes, o Manual de Oslo (OCDE, 2005), elaborado pela Organização para Cooperação e Desenvolvimento Econômico, discute como a inovação pode ocasionar mudanças no nível da empresa individual. Assim, concentra-se em processos e produtos significativamente aprimorados, reconhecendo que as inovações organizacionais podem resultar em melhoras significativas no desempenho das empresas.

Nesse contexto, a inovação de produtos é caracterizada pela "[...] introdução de um bem ou serviço tecnologicamente novo ou substancialmente modificado [...]" no mercado. Para ser categorizado nessa inovação, os novos produtos podem ser melhorados por meio da utilização de variáveis técnicas como o "[...] uso de novos materiais, uso de novos produtos intermediários, novas peças funcionais, uso de tecnologia radicalmente nova e novas funções fundamentais" (OCDE, 2005, p. 121 e 131). Também se considera inovação quando ocorre a alteração da qualidade, funções, quantidade de clientes atendidos e público-alvo (FERNANDES, 2003).

Com esse tipo de inovação, a empresa obtém posição de liderança devido ao tempo que os concorrentes levam para copiá-la ou em função de uma patente adquiria. Essa posição monopolista permite fixar um preço mais alto do que seria possível em um mercado competitivo. Contudo, devem reduzir custos para continuar obtendo lucro e serem competitivas frente aos concorrentes que inevitavelmente tentarão imitá-la, investindo, principalmente em tecnologia aplicada (FERNANDES, 2003; OCDE, 2005).

Por outro lado, quando ocorrem alterações nos métodos de produção, de modo a reduzir custos ou melhorar a qualidade de um produto existente, ou, ainda, quando se desenvolvem novos processos para fabricar um produto novo ou melhorado, tem-se a inovação de processos (MATTOS; GUIMARÃES, 2013; TIDD; BESSANT, 2015). Sucintamente, ela diz respeito às mudanças na forma em que os produtos $e$ serviços são criados e entregues, apresentando efeito direto sobre a produção de produtos para o mercado (OCDE, 2005).

Retomando o debate acerca das inovações organizacionais, apresentado pela OCDE (2005), os autores Davila, Epstein e Shelton (2007) corroboram que a estratégia de inovação organizacional precisa adaptar-se à situação do negócio e ser transparente para todos os seus membros. A companhia deve aplicar seus recursos, em áreas estratégicas que proporcionam maior retorno sobre o investimento, do contrário pode enfrentar resultados piores do que os esperados. A decisão de qual estratégia de inovação melhor se adapta à situação da concorrência externa $e$ do mercado $e$ às condições internas da empresa constitui responsabilidade da equipe de altos executivos, e em última análise é tarefa do diretor geral.

\subsection{Inovação Ambiental}

A tentativa de conceituar inovação ambiental baseia-se em uma perspectiva evolutiva da inovação (WITT, 2013), segundo a qual a inovação surge por meio de um processo sistêmico que se refere à inter-relação e à interação dinâmica entre diferentes atores e fatores internos e externos que influenciam o processo 
de inovação. Essas premissas motivam a exploração do vasto leque da ecoinovação e da análise das mudanças ocorridas em várias dimensões da ecoinovação, que consistem nos aspectos de design, do usuário, dos produtos, dos serviços e da governança (DEL RÍO et al., 2011).

De acordo com Larson (2011), a inovação ambiental é uma força emergente e fundamental para as mudanças nos negócios e nas sociedades. Trata-se de uma oportunidade potencial para promover a transformação tecnológica de produtos e de mercados, além de distinguir-se como uma área de oportunidade para empreendedores e de atuar como uma força de destruição criativa (SCHUMPETER, 1982). Nesse sentido, Barbieri (2011) defende que uma organização inovadora sustentável é aquela que atua no sentido de alcançar o desenvolvimento social, tecnologicamente prudente e economicamente eficiente.

Assim, a inovação ambiental pode ser interpretada como a utilização de uma gama de insumos (matéria-prima, energia e mão de obra) de maneira mais produtiva, compensando, dessa forma, os custos para a redução do impacto ambiental e resolvendo o impasse da ecologia versus economia (PORTER; VAN DER LINDE, 1995). Dessa forma, as ecoinovações oportunizam a criação de novos produtos a preços competitivos, com processos, sistemas, serviços e procedimentos concebidos para satisfazer às necessidades humanas e proporcionar uma melhor qualidade de vida para todos, com o uso mínimo de recursos naturais por unidade de produção e com uma liberação mínima de substâncias tóxicas (O'BRIEN et al., 2012).

Em termos conceituais, inovação ambiental é a fabricação de um produto, processo de produção, serviço, ferramenta de gestão, modo de negócio novo que resulta, ao longo de sua implementação ou uso, em redução do impacto ambiental, se comparado a alternativas anteriores. Desse modo, a principal diferença entre inovação ambiental de uma inovação tradicional é o ganho ambiental gerado, quando comparado às tecnologias disponíveis para o mesmo fim. Essa perspectiva deixa os fatores lucro e retorno financeiro em segundo plano e prioriza o benefício ambiental, pois este é difícil mensurar em termos econômicos (KEMP; PEARSON, 2007).

Murillo-Luna et al. (2008) corroboram que sob uma ótica inovativa, apenas as ações proativas po- dem ser consideradas uma inovação ambiental, por apresentar algo novo à sociedade. Sendo assim, a preocupação com o meio ambiente está estreitamente relacionada com a inovação, devido seu impacto sobre o meio ambiente e a sociedade, já que elas determinam o que será produzido, como será produzido e como serão distribuídos os resultados do esforço coletivo. Os autores Larson (2011) e Barbieri (2011) completam que as organizações inovadoras sustentáveis são aquelas que geram inovações desse tipo, de modo contínuo.

Embora a literatura defenda que a inovação ambiental objetiva principalmente obter a eficiência na produção, a minimização do consumo de recursos naturais não renováveis, a emissão de poluentes $e$ os produtos recicláveis, a fim de alcançar um retorno financeiro superior, ainda há restrições para diversas empresas introduzirem tais práticas (DONAIRE, 2007). Entre os diversos motivos para isso, Straete (2004), e Elzen e Wieczorek (2005) afirmam que a inovação em sistemas industriais com forte interpendência de componentes é complexa, pois não pode ser facilmente separada de mudanças estruturais, econômicas, sociais e culturas profundas.

\section{UnidAde de ANÁlise}

O segmento metalmecânico é um setor bastante expressivo na economia brasileira, representando no ano de 2013 um percentual de 35,2\% do PIB industrial nacional. No Estado do Rio Grande do Sul, esse macrossetor representa $37,6 \%$ do PIB industrial. É composto de empresas de todos os portes, desde a metalurgia básica até a fabricação de produtos em geral, máquinas e equipamentos, e agrega, também, produção de aparelhos e materiais elétricos de comunicação e veículos automotores (FIERGS, 2014; SINMETAL, 2014).

Na região Sul do Brasil, destaca-se o estado do Rio Grande do Sul, que conta com aproximadamente 9,8 mil estabelecimentos no setor, o que equivale a $41 \%$ de todos os estabelecimentos dessa indústria, situados nos três estados que constituem o Sul do país. A importância do setor metalmecânico gaúcho também fica evidente quando se observa que ele está posicionado em segundo lugar em termos de concentração de estabelecimentos industriais desse setor, representando 
12,5\% do total nacional (FIERGS, 2011; MTE/RAIS, 2012). Cabe mencionar que, no segmento metalmecânico, ocorre predominância de estabelecimentos de micro e pequeno porte, sendo estes responsáveis por $95,5 \%$ do total brasileiro e por $96,35 \%$ do total gaúcho (FIERGS, 2011).

Localizada a aproximadamente 40 quilômetros de Porto Alegre, a região do Vale do Rio dos Sinos é conhecida como uma das áreas de maior potencial econômico e industrial do Estado do Rio Grande do Sul. Em termos socioeconômicos, essa região detém o terceiro maior PIB do Estado, ficando atrás somente do arranjo produtivo local da Serra e da região Metropolitana Delta do Jacuí, o qual inclui a cidade de Porto Alegre e o polo Petroquímico de Triunfo (FEE, 2014). Os bons indicadores econômicos e sociais decorrem da intensa atividade produtiva, com destaque na indústria para os setores coureiro-calçadista e metalmecânico (MTE/RAIS, 2012).

O Vale do Rio dos Sinos, cuja abreviatura comumente utilizada é Vale dos Sinos, é uma região de $1.398,5 \mathrm{~km}^{2}$, composta de 14 municípios, de acordo com definição do Conselho Regional de Desenvolvimento do Vale do Rio dos Sinos (COREDE, 2014). São eles: Araricá, Campo Bom, Canoas, Dois Irmãos, Estância Velha, Esteio, Ivoti, Nova Hartz, Nova Santa Rita, Novo Hamburgo, Portão, São Leopoldo, Sapiranga e Sapucaia do Sul.

\section{Método}

Nesta pesquisa realizou-se uma survey por meio do questionário construído à luz de vertentes teóricas revisadas. O questionário foi construído com questões fechadas, utilizando a escala Likert de cinco pontos. Essa técnica consiste em um conjunto de afirmações nas quais o respondente demonstra sua opinião em um sistema de cinco categorias de resposta, que variam de "discordo totalmente" a "concordo totalmente".

A etapa de validação do questionário ocorreu por meio da técnica Delphi, que é um método sistematizado de julgamento de informações para obter consenso de especialistas, por meio de validações articuladas em fases, denominadas de rodadas de revisão do questionário (WRIGHT; JOHNSON; BIAZZI, 1991). O número de rodadas do questionário depende, normalmente, da natureza do grupo e sua homogeneidade, sendo que a seleção dos experts é considerada não aleatória, por conveniência e intencional e se justifica uma vez que o interesse é selecionar especialistas na temática de estudo (KAYO; SECURATO, 1997; GIOVINAZZO, 2001). Nesse sentido, foram escolhidos três experts da área, para compor o grupo de especialistas sendo necessárias três rodadas de revisão. Suas principais contribuições se relacionaram à clareza de linguagem, não sendo necessárias a exclusão ou a inclusão de questões.

Após a etapa de validação com os experts, realizou-se um pré-teste com colaboradores em uma metalúrgica. Foram obtidos 18 questionários, sendo esses dados submetidos a uma análise estatística por meio do coeficiente alfa de Cronbach, com a finalidade de verificar a consistência interna dos elementos do questionário. O coeficiente alfa de Cronbach é um índice utilizado para medir a confiabilidade, ou seja, para avaliar a magnitude em que os itens de um instrumento estão correlacionados, sendo estimado por meio de procedimentos empíricos observando as pontuações dos sujeitos investigados (CORTINA, 1993).

O coeficiente alfa de Cronbach varia de 0 a 1 e, quanto mais elevada a contagem, maior a confiabilidade da escala. Um valor de pelo menos 0,7 reflete uma fidedignidade aceitável (NUNNALY, 1978). Os questionários da empresa piloto foram submetidos ao cálculo do coeficiente alfa de Cronbach, a partir do programa estatístico SPSS ${ }^{\circledR}$ versão 20 (Statistical Software for Social Sciences), obtendo-se um valor de 0,945 , isto é, o resultado demostra alta consistência interna do questionário.

Concluída a etapa de validação do questionário, determinou-se a população do estudo. No Brasil, devido às dificuldades de acessos aos bancos de dados, tem-se utilizado o critério de conveniência para a seleção da população, devido à facilidade de acesso proporcionada por entidades representativas de empresas (SAMPAIO, 2000; PERIN, 2001). No caso deste estudo, estabeleceu-se que o universo da pesquisa seriam empresas associadas à Federação das Indústrias do Rio Grande do Sul (FIERGS).

A partir do banco de dados da FIERGS (2013), foram delimitadas as empresas do segmento metalmecânico, da região do Vale dos Sinos que, nesta pesquisa, representam o universo. Ressalta-se que, no referido banco de dados, as empresas são categorizadas 
por segmento de produto e, em alguns casos, a mesma empresa constava em duplicidade. Assim, optou-se pelas empresas de "fabricação de produtos de metal, exceto máquinas e equipamentos", conforme filtro de dados da FIERGS, pois este é o segmento com maior número de cadastros ativos.

Dessa forma, o universo foi constituído de 305 empresas, distribuídas nas 14 cidades da região do Vale dos Sinos. Para esse universo calculou-se uma amostragem com nível de confiança de $95 \%$ e margem de erro de $5 \%$, o que totalizou 177 companhias. Contudo, durante a etapa de coleta de dados, algumas empresas não demonstraram interesse em participar da pesquisa, obtendo-se assim 159 questionários válidos. O Quadro 1 ilustra detalhadamente a distribuição amostral, por cidade, da região pesquisada.

\begin{tabular}{|c|c|c|c|}
\hline CIDADE & Universo & AMOSTRA & $\begin{array}{c}\text { QUESTIONÁRIOS } \\
\text { RESPONDIDOS }\end{array}$ \\
\hline Araricá & 2 & 2 & 0 \\
\hline Campo Bom & 17 & 10 & 10 \\
\hline Canoas & 52 & 30 & 27 \\
\hline Dois Irmãos & 0 & 0 & 0 \\
\hline Estância Velha & 16 & 9 & 9 \\
\hline Esteio & 20 & 12 & 12 \\
\hline Ivoti & 2 & 2 & 2 \\
\hline Nova Hartz & 3 & 2 & 2 \\
\hline Nova Santa Rita & 7 & 4 & 4 \\
\hline Novo Hamburgo & 81 & 46 & 43 \\
\hline Portão & 3 & 2 & 2 \\
\hline São Leopoldo & 67 & 38 & 28 \\
\hline Sapiranga & 14 & 8 & 8 \\
\hline Sapucaia do Sul & 21 & 12 & 12 \\
\hline Total do Universo & 305 & 177 & \\
\hline
\end{tabular}

Quadro 1: Detalhamento do universo da pesquisa Fonte: Elaborado pelos autores com base em FIERGS (2013) e dados da pesquisa

Os dados foram coletados por meio de entrevistas telefônicas, com auxílio de computador pessoal, pelo Centro de Pesquisa e Planejamento (CPP) da Universidade Feevale. A coleta dos dados ocorreu no período de 23 de julho de 2014 a 20 de agosto de 2014, sendo monitoradas pelo supervisor da equipe. O tempo médio de entrevista foi calculado em oito minutos. O questionário utilizado encontra-se no Apêndice A.

O conjunto de 159 entrevistas foi efetivado, constituindo um banco de dados com a totalidade de informações geradas, garantindo a inexistência de respostas fora de escalas, reduzindo erros de leitura $e$ digitação. Este banco de dados foi analisado, por meio do cálculo de correlação bivariada, utilizando-se como coeficiente de correlação o coeficiente de Spearman, e intervalos de confiança de $95 \%$.

De acordo com Bunchaft e Kellner (2002), o coeficiente de Spearman varia entre -1 e 1. Quanto mais próximo estiver desses extremos, maior será a associação entre as variáveis. Esses autores ratificam que no relacionamento correlacional, não se tem controle sobre as variáveis estudadas. Estas são observadas como ocorrem no ambiente natural, sem nenhuma interferência, isto é, as duas variáveis são aleatórias. Para realizar a correlação entre as variáveis ambientais e de inovação, utilizou-se o software SPSS ${ }^{\circledast}$, cujo cálculo resultou em uma planilha extensa, visto que o questionário aplicado possui 23 variáveis relacionadas às questões ambientais e 34 variáveis para a temática inovação.

Com o propósito de facilitar a apresentação dos dados advindos do cálculo supramencionado, foram realizados alguns ajustes estruturais, sendo apresentados apenas os resultados que possuem relação com o objetivo da análise de correlação. Dessa forma, os quadros expostos a seguir, com a discussão dos resultados, formam propostas com a finalidade de verificar quais variáveis possuem estruturação semelhante nas organizações, selecionando, para isso, as variáveis que apresentaram os maiores valores no cálculo da correlação.

\section{Análise e Discussão dos Resultados}

Para Schumpeter (1982), a introdução de uma inovação, no sistema econômico, visa à sobrevivência organizacional e à obtenção do lucro, além de criar diferencial competitivo. Porter (1989) adverte ainda que a introdução de uma inovação permite a redução de custos ou a diferenciação no mercado. Nesse contexto, no Quadro 2 apresenta-se as variáveis de correlação das estratégias da inovação com as variáveis ambientais, com base nas respostas dos colaboradores entrevistados nas metalúrgicas do Vale dos Sinos. 


\begin{tabular}{|c|c|c|}
\hline $\begin{array}{c}\text { VARIÁVEIS REFERENTES } \\
\text { À INOVAÇÃO }\end{array}$ & VARIÁVEIS REFERENTE À TEMÁTICA AMBIENTAL & SPEARMAN \\
\hline \multirow{3}{*}{$\begin{array}{l}\text { A inovação deve } \\
\text { contribuir para a } \\
\text { redução de custos. }\end{array}$} & $\begin{array}{c}\text { A empresa preocupa-se em modificar ou substituir os processos } \\
\text { de modo a torná-los ambientalmente favoráveis. }\end{array}$ &, 514 \\
\hline & Existe preocupação em eliminar as emissões tóxicas. & ,424 \\
\hline & $\begin{array}{l}\text { A empresa adota práticas de proteção ambiental, pois se } \\
\text { preocupa com o impacto ambiental da sua atividade. }\end{array}$ & ,496 \\
\hline \multirow{5}{*}{$\begin{array}{l}\text { A inovação deve } \\
\text { contribuir para } \\
\text { a diferenciação } \\
\text { no mercado. }\end{array}$} & A dimensão ambiental está presente na estratégia empresarial. & ,366 \\
\hline & A preocupação com o meio ambiente está expressa na missão e valores da companhia. & ,377 \\
\hline & $\begin{array}{c}\text { A empresa preocupa-se em modificar ou substituir os processos } \\
\text { de modo a torná-los ambientalmente favoráveis. }\end{array}$ &, 541 \\
\hline & Existe preocupação em eliminar as emissões tóxicas. & ,415 \\
\hline & $\begin{array}{l}\text { A empresa adota práticas de proteção ambiental, pois se } \\
\text { preocupa com o impacto ambiental da sua atividade. }\end{array}$ &, 509 \\
\hline
\end{tabular}

Quadro 2: Correlação entre estratégias de inovação e variáveis ambientais

Fonte: Elaborado pelos autores deste artigo

Assim como exposto por Souza (2002), a presença da relação entre as estratégias da inovação com "a empresa preocupa-se em modificar ou substituir os processos de modo a torná-los ambientalmente favoráveis", contribui com o debate teórico de que empresas que competem em mercados de commodities tendem a dirigir suas iniciativas ambientais para processos, a fim de melhorar a eficiência e reduzir custos. Por outro lado, empresas que competem em mercados de elevada diferenciação direcionam as ações ambientais para produtos.

Destarte, quando as companhias aliam as vantagens econômicas com as ecológicas, por meio da aplicação de inovações tecnológicas, elas tendem a reduzir o impacto ambiental da sua atividade $e$ assim desenvolver produtos sustentáveis (MANZINI; VEZZOLI, 2002). Essa base conceitual pode ser corroborada por meio das correlações estabelecidas entre as variáveis explicitadas anteriormente, a inovação $e$ as práticas ambientais, tendo em vista a complementariedade desses conceitos também nos resultados desta pesquisa.

Quando o critério de correlação diz respeito exclusivamente ao desenvolvimento de produtos, levando em consideração o impacto ambiental das matérias-primas utilizadas, obtêm-se as correlações constantes no Quadro 3.

\begin{tabular}{|c|c|c|}
\hline $\begin{array}{l}\text { VARIÁVEIS REFERENTES AO } \\
\text { DESENVOLVIMENTO DE PRODUTOS }\end{array}$ & VARIÁVEIS REFERENTE À TEMÁTICA AMBIENTAL & SPEARMAN \\
\hline \multirow{11}{*}{$\begin{array}{l}\text { Quando está sendo } \\
\text { desenvolvido um novo produto, } \\
\text { a empresa leva em consideração } \\
\text { o impacto ambiental das } \\
\text { matérias-primas utilizadas. }\end{array}$} & A empresa adota práticas de proteção ambiental a fim de tornar-se mais competitiva. & ,358 \\
\hline & Existe preocupação em reduzir os materiais de embalagem. & ,385 \\
\hline & $\begin{array}{l}\text { Existe envolvimento de todos os setores da empresa } \\
\text { na busca pela qualidade ambiental. }\end{array}$ & ,426 \\
\hline & A gestão ambiental é tarefa de todos os setores da empresa. & ,429 \\
\hline & $\begin{array}{l}\text { A empresa utiliza alguma tecnologia limpa, ou processo de tecnologia } \\
\text { de produção integrada para reduzir a produção de resíduos. }\end{array}$ & ,439 \\
\hline & $\begin{array}{l}\text { A empresa adota práticas de proteção ambiental, pois se } \\
\text { preocupa com o impacto ambiental da sua atividade. }\end{array}$ & , 454 \\
\hline & Existe preocupação em eliminar produtos químicos. & ,468 \\
\hline & $\begin{array}{c}\text { A empresa busca opções de negócios em função das características } \\
\text { ecológicas de produtos, processos ou serviços. }\end{array}$ & ,475 \\
\hline & Existe preocupação em eliminar as emissões tóxicas. & ,485 \\
\hline & $\begin{array}{l}\text { A empresa preocupa-se em modificar ou substituir produtos } \\
\text { de modo a torná-los ambientalmente favoráveis. }\end{array}$ & ,499 \\
\hline & $\begin{array}{c}\text { A empresa preocupa-se em modificar ou substituir os processos } \\
\text { de modo a torná-los ambientalmente favoráveis. }\end{array}$ &, 502 \\
\hline
\end{tabular}

Quadro 3: Correlação entre desenvolvido de um novo produto e variáveis ambientais

Fonte: Elaborado pelos autores deste artigo 
Confirmando o que foi exposto por Andrade, Tachizawa e Carvalho (2002), os dados nesta categoria da análise de correlação sinalizam que o desenvolvimento de produtos sustentáveis refere-se ao controle ambiental integrado às boas práticas dos processos produtivos. Isso se deve à correlação moderada positiva e mais forte dentre todas as outras variáreis atribuída à afirmação de que "a empresa preocupa-se em modificar ou substituir os processos de modo a torná-los ambientalmente favoráveis".

É possível constatar correlações importantes, mas não tão significativas, com a assertiva de que "a empresa adota práticas de proteção ambiental a fim de tornar-se mais competitiva", com a variável referente ao desenvolvimento de um novo produto levando em consideração o impacto ambiental das matérias-primas utilizadas. A presença dessa correlação denota que as empresas metalúrgicas do Vale dos Sinos estão alinhadas com os conceitos expostos por Porter e Van Der Linde (1995), Oliveira e Serra (2010) e Grael e Oliveira (2010), referente á identificação e à caracterização de relações entre a inovação ambiental e a construção de vantagens absolutas sobre outras empresas.

Para Grael e Oliveira (2010), o mapeamento de todos os processos e suas inter-relações permitem identificar relações positivas entre produtos, linhas de produção e setores. Dessa forma, torna-se possível fazer uma reestruturação de pontos específicos e gerar diferenciais para os sistemas que estão sendo integrados e para a competitividade da empresa.
Além disso, Porter e Van Der Linde (1995), Oliveira e Serra (2010) e Grael e Oliveira (2010) entendem que a competitividade advinda da modernização dos projetos de desenvolvimento de produtos que se preocupa com o impacto ambiental das matérias-primas utilizadas gera economias em função da redução do desperdício, da emissão de resíduos e de poluentes tóxicos. Essa constatação foi corroborada com a correlação positiva moderada entre as seguintes variáveis: existe preocupação em eliminar produtos químicos; existe preocupação em eliminar as emissões tóxicas; $e$ a empresa utiliza alguma tecnologia limpa, ou processo de tecnologia de produção integrada para reduzir a produção de resíduos.

Cumpre destacar os fatores motivadores na adoção de práticas ambientais sinalizados por Barbieri (2011): obrigatoriedade legal e fatores relacionados à competitividade dos negócios. Por meio das correlações apresentadas no Quadro 2, percebe-se que os entrevistados possuem entendimento acerca das oportunidades de negócio advindas da adoção de práticas ambientais. Contudo, conforme sinalizado por Souza (2002), existe uma inconsistência entre o que as empresas professam e planejam em termos ambientais, com o que elas efetivamente fazem.

Ainda com relação à inovação de produto, as variáveis que apresentaram as correlações mais fortes com as dimensões ambientais do estudo, podem ser verificadas no Quadro 4.

\begin{tabular}{|c|c|c|}
\hline $\begin{array}{l}\text { VARIÁVEIS REFERENTES À } \\
\text { INOVAÇÃ̃o }\end{array}$ & VARIÁVEIS REFERENTE À TEMÁTICA AMBIENTAL & SPEARMAN \\
\hline \multirow{5}{*}{$\begin{array}{l}\text { As alterações de produtos são } \\
\text { registradas em sistema interno. }\end{array}$} & $\begin{array}{c}\text { A empresa preocupa-se em modificar ou substituir os processos } \\
\text { de modo a torná-los ambientalmente favoráveis. }\end{array}$ & 0,395 \\
\hline & $\begin{array}{c}\text { A empresa busca opções de negócios em função das características } \\
\text { ecológicas de produtos, processos ou serviços. }\end{array}$ & 0,409 \\
\hline & $\begin{array}{c}\text { Existe envolvimento de todos os setores da empresa } \\
\text { na busca pela qualidade ambiental. }\end{array}$ & 0,42 \\
\hline & $\begin{array}{l}\text { A empresa adota práticas de proteção ambiental, pois se } \\
\text { preocupa com o impacto ambiental da sua atividade. }\end{array}$ & 0,423 \\
\hline & A gestão ambiental é tarefa de todos os setores da empresa. & 0,429 \\
\hline \multirow{4}{*}{$\begin{array}{l}\text { As melhorias de produtos } \\
\text { são compartilhadas com } \\
\text { os colaboradores. }\end{array}$} & Os setores interagem entre si para a tomada de decisões em questões ambientais. & 0,433 \\
\hline & $\begin{array}{l}\text { A empresa preocupa-se em modificar ou substituir os processos } \\
\text { de modo a torná-los ambientalmente favoráveis. }\end{array}$ & 0,458 \\
\hline & A gestão ambiental é tarefa de todos os setores da empresa. & 0,481 \\
\hline & $\begin{array}{l}\text { Existe envolvimento de todos os setores da empresa } \\
\text { na busca pela qualidade ambiental. }\end{array}$ & 0,495 \\
\hline \multirow{3}{*}{$\begin{array}{c}\text { Todo tipo de mudanças } \\
\text { de produtos está sujeita } \\
\text { à aprovação prévia da } \\
\text { direção da empresa. }\end{array}$} & $\begin{array}{l}\text { Existe envolvimento de todos os setores da empresa } \\
\text { na busca pela qualidade ambiental. }\end{array}$ & 0,402 \\
\hline & $\begin{array}{l}\text { A empresa adota práticas de proteção ambiental, pois se } \\
\text { preocupa com o impacto ambiental da sua atividade. }\end{array}$ & 0,453 \\
\hline & $\begin{array}{l}\text { A empresa preocupa-se em modificar ou substituir os processos } \\
\text { de modo a torná-los ambientalmente favoráveis. }\end{array}$ & 0,48 \\
\hline
\end{tabular}

Quadro 4: Correlação entre desenvolvido de um novo produto e variáveis ambientais

Fonte: Elaborado pelos autores deste artigo 
As variáveis que convergem nas três categorias referentes à temática inovação, concernem para a existência do envolvimento de todos os setores na busca pela qualidade ambiental; preocupação da empresa em modificar ou substituir os processos de modo a torná-los ambientalmente favoráveis. Esta última apresentou correlação mais forte com a com a aprovação prévia da direção da empresa para todo $e$ qualquer tipo de mudança de produtos. De tal modo, como exposto por Davila, Epstein e Shelton (2007), a decisão de qual estratégia de inovação melhor se adapta à situação da empresa, neste caso específico na adoção de estratégias ambientais que resultem em processos ambientalmente favoráveis, é tarefa da direção, na maioria das empresas pesquisadas.

Além disso, tal como apresentado por Dyllick et al. (2000), Beard e Rees (2000) e Dias (2011), a gestão ambiental abrange todos os setores necessários ao planejamento, execução, revisão e desenvolvimento de uma política ambiental da organização. As correlações moderadas entre as variáveis em discussão sugerem que o envolvimento dos colaboradores na busca pela qualidade ambiental, representa a vontade organizacional em priorizar as práticas de inovação e de gestão ambiental, uma vez que todo tipo de mudanças de produtos está sujeita à aprovação prévia da direção da empresa.

Nielsen e Wenzel (2002) ressaltam que as decisões mais importantes concernentes às propriedades ambientais de um determinado produto, são tomadas nas primeiras fases do projeto. Nesse sentido, este debate teórico pode ser ratificado por meio das correlações moderadas positivas entre as variáveis de que as melhorias de produtos são compartilhadas com os colaboradores; os setores interagem entre si para a tomada de decisões em questões ambientais; e a gestão ambiental é tarefa de todos os setores da empresa, presentes nas empresas que participaram desta pesquisa.

Isso se deve ao fato de que, sendo a gestão ambiental tarefa de todos os colaboradores e havendo interações entre eles, as propriedades ambientais de determinado produto ou processo são mais facilmente aprimoradas. Mais do que isto, a interação dinâmica entre diferentes setores influenciam o processo de inovação, conforme exposto por (DEL RíO et al., 2011). Os autores entendem que, a inter-relação entre colaboradores motivam a exploração do vasto leque da ecoinovação e da análise das mudanças ocorridas em várias dimensões. Complementado ao que foi exposto pelos autores revisados, as correlações propostas no Quadro $n 3$ sugerem que esse processo pode ser facilitado se as alterações de produtos forem registradas em sistema interno, pois se ocorrer mudança do quadro funcional da organização o conhecimento gerado até então não se perde.

Com relação à inovação de processos, as variáveis que apresentaram correlações mais fortes com as dimensões ambientais referem-se às práticas de inovação que contribuem para alcançar maior eficiência operacional; a inovação depende do investimento em renovação do parque fabril - máquinas e equipamentos. Os resultados dessa correlação podem ser verificados no Quadro 5.

\begin{tabular}{|c|c|c|}
\hline $\begin{array}{l}\text { VARIÁVEIS REFE- } \\
\text { RENTES À INOVA- } \\
\text { ÇÃO DE PROCESSO }\end{array}$ & VARIÁVEIS REFERENTE À TEMÁTICA AMBIENTAL & SPEARMAN \\
\hline \multirow{6}{*}{$\begin{array}{l}\text { O foco central } \\
\text { da inovação são } \\
\text { os processos. }\end{array}$} & $\begin{array}{c}\text { A empresa busca opções de negócios em função das características } \\
\text { ecológicas de produtos, processos ou serviços. }\end{array}$ & ,367 \\
\hline & A gestão ambiental é tarefa de todos os setores da empresa. & ,368 \\
\hline & A preocupação com o meio ambiente está expressa na missão e valores da companhia. & ,373 \\
\hline & Existe envolvimento de todos os setores da empresa na busca pela qualidade ambiental. & ,396 \\
\hline & $\begin{array}{l}\text { A empresa adota práticas de proteção ambiental, pois se preocupa } \\
\text { com o impacto ambiental da sua atividade. }\end{array}$ & ,435 \\
\hline & $\begin{array}{l}\text { A empresa preocupa-se em modificar ou substituir os processos } \\
\text { de modo a torná-los ambientalmente favoráveis. }\end{array}$ & ,438 \\
\hline \multirow{2}{*}{$\begin{array}{l}\text { As práticas de } \\
\text { inovação devem } \\
\text { contribuir para } \\
\text { maior eficiência } \\
\text { operacional. }\end{array}$} & $\begin{array}{l}\text { A empresa preocupa-se em modificar ou substituir os processos } \\
\text { de modo a torná-los ambientalmente favoráveis. }\end{array}$ & ,432 \\
\hline & $\begin{array}{l}\text { A empresa adota práticas de proteção ambiental, pois se preocupa } \\
\text { com o impacto ambiental da sua atividade. }\end{array}$ &, 544 \\
\hline
\end{tabular}




\begin{tabular}{|c|c|c|c|}
\hline & Existe preocupação em eliminar as emissões tóxicas. &, 362 \\
\hline $\begin{array}{c}\text { A inovação } \\
\text { depende do } \\
\text { investimento } \\
\text { em renovação } \\
\text { do parque fabril } \\
\text { - máquinas e } \\
\text { equipamentos. }\end{array}$ & A preocupação com o meio ambiente está expressa na missão e valores da companhia. &, 437 \\
\hline
\end{tabular}

Quadro 5: Correlação entre inovação de processo e variáveis ambientais

Fonte: Elaborado pelos autores deste artigo

Em termos de inovação de processos, os respondentes da pesquisa, correlacionam-na, de forma moderada, com as assertivas de que a empresa adota práticas de proteção ambiental, pois se preocupa com o impacto ambiental da sua atividade; e a empresa preocupa-se em modificar ou substituir os processos de modo a torná-los ambientalmente favoráveis. Estas correlações se percebem quando a perspectiva de análise voltava-se para a inovação de produtos. Constata-se que os profissionais entrevistados concordam com o que foi exposto por Nascimento (2001), Manzini e Vezzoli (2002) e Sanches (2000), uma vez que esses autores apresentam, como traço comum, a reflexão de que as empresas buscam aliar as práticas ambientais com a inovação de produtos e processos como forma de reduzir o impacto ambiental da sua atividade.
Vale destacar que Sanches (2000) entende que algumas práticas ambientais conduzem ao desempenho ambiental lucrativo e responsável. Dentre elas, destaca-se: praticar a conservação e atentar a cada detalhe associado com os processos; modificar ou substituir processos, produtos e serviços de modo a torná-los ambientalmente favoráveis; reduzir os materiais de embalagem, eliminar produtos químicos $e$ emissões tóxicas; recuperar, por meio de reciclagem e reutilização, resíduos e produtos secundários; e descobrir nichos verdes de mercado, atendendo-os com novos produtos e serviços. Quanto a essa abordagem teórica, no Quadro 6, é possível identificar as variáveis ambientais que se relacionam moderadamente com a inovação de processos, confirmando o que foi afirmado por Sanches (2000).

\begin{tabular}{|c|c|c|}
\hline $\begin{array}{l}\text { VARIÁVEIS REFERENTES À INOVA- } \\
\text { ÇÃO DE PROCESSO }\end{array}$ & VARIÁVEIS REFERENTE À TEMÁTICA AMBIENTAL & SPEARMAN \\
\hline \multirow{7}{*}{$\begin{array}{l}\text { Todo tipo de mudanças de } \\
\text { processos está sujeita à aprovação } \\
\text { prévia da direção da empresa. }\end{array}$} & A empresa possui um sistema de tratamento e eliminação de resíduos. & ,382 \\
\hline & A gestão ambiental é tarefa de todos os setores da empresa. & ,409 \\
\hline & $\begin{array}{c}\text { A empresa possui controle de poluição para impedir } \\
\text { o lançamento de poluentes na água. }\end{array}$ & ,423 \\
\hline & $\begin{array}{l}\text { A empresa adota práticas de proteção ambiental, pois se } \\
\text { preocupa com o impacto ambiental da sua atividade. }\end{array}$ & ,430 \\
\hline & Existe preocupação em eliminar as emissões tóxicas. & , 438 \\
\hline & $\begin{array}{l}\text { Existe envolvimento de todos os setores da empresa } \\
\text { na busca pela qualidade ambiental. }\end{array}$ & ,461 \\
\hline & $\begin{array}{c}\text { A empresa preocupa-se em modificar ou substituir os processos } \\
\text { de modo a torná-los ambientalmente favoráveis. }\end{array}$ & ,490 \\
\hline
\end{tabular}




\begin{tabular}{|c|c|c|}
\hline \multirow{8}{*}{$\begin{array}{l}\text { As melhorias de processos } \\
\text { são compartilhadas com } \\
\text { os colaboradores. }\end{array}$} & Existe preocupação em eliminar produtos químicos. & ,384 \\
\hline & $\begin{array}{l}\text { A empresa preocupa-se em modificar ou substituir produtos } \\
\text { de modo a torná-los ambientalmente favoráveis. }\end{array}$ & ,401 \\
\hline & $\begin{array}{l}\text { Os custos provenientes da gestão ambiental são determinados por } \\
\text { meio dos custos ambientais no processo de gestão financeira. }\end{array}$ & ,413 \\
\hline & Existe preocupação em eliminar as emissões tóxicas. & ,421 \\
\hline & $\begin{array}{l}\text { Existe envolvimento de todos os setores da empresa } \\
\text { na busca pela qualidade ambiental. }\end{array}$ & ,469 \\
\hline & A gestão ambiental é tarefa de todos os setores da empresa. & ,474 \\
\hline & $\begin{array}{c}\text { A empresa busca opções de negócios em função das características } \\
\text { ecológicas de produtos, processos ou serviços. }\end{array}$ & ,482 \\
\hline & $\begin{array}{c}\text { A empresa preocupa-se em modificar ou substituir os processos } \\
\text { de modo a torná-los ambientalmente favoráveis. }\end{array}$ &, 501 \\
\hline
\end{tabular}

Quadro 6: Correlação entre inovação de processo e variáveis ambientais

Fonte: Elaborado pelos autores deste artigo

Assim como na inovação de produtos, as variáveis ambientais relacionaram-se com "todo tipo de mudanças de processos está sujeita a aprovação prévia da direção da empresa" e "as melhorias de processos são compartilhadas com os colaboradores". Nesse sentido, é possível destacar que as variáveis referentes ao envolvimento de todos os setores da empresa na busca pela qualidade ambiental; e a gestão ambiental é tarefa de todos os setores da empresa, também se correlacionaram com as variáveis de análise referentes aos processos organizacionais.
Conforme exposto por Murillo-Luna et al. (2008), Larson (2011), Barbieri (2011), Kemp e Pearson (2007) e Arruda et al. (2014), a preocupação com o meio ambiente está estreitamente relacionada com a inovação, devido a seu impacto sobre o meio ambiente e a sociedade, já que ela determina o que será produzido, como será produzido e como serão distribuídos os produtos. A fim de analisar, mais profundamente, quais práticas ambientais as metalúrgicas entrevistadas percebem como as que mais contribuem ao processo de inovação, estruturou-se o Quadro 7.

\begin{tabular}{|c|c|c|}
\hline Variável referente à inovação & Variáveis referente à temática ambiental & Spearman \\
\hline \multirow{8}{*}{$\begin{array}{c}\text { A empresa entende que, } \\
\text { ao desenvolver inovação } \\
\text { contribui para as boas práticas } \\
\text { de gestão ambiental. }\end{array}$} & $\begin{array}{l}\text { A empresa preocupa-se em modificar ou substituir produtos } \\
\text { de modo a torná-los ambientalmente favoráveis. }\end{array}$ & , 405 \\
\hline & Existe preocupação em reduzir os materiais de embalagem. & , 408 \\
\hline & $\begin{array}{l}\text { A empresa preocupa-se em modificar ou substituir os processos } \\
\text { de modo a torná-los ambientalmente favoráveis. }\end{array}$ & , 459 \\
\hline & Existe preocupação em eliminar as emissões tóxicas. & ,464 \\
\hline & A gestão ambiental é tarefa de todos os setores da empresa. & ,490 \\
\hline & Existe preocupação em eliminar produtos químicos. &, 504 \\
\hline & $\begin{array}{c}\text { A preocupação com o meio ambiente está expressa } \\
\text { na missão e valores da companhia. }\end{array}$ &, 531 \\
\hline & $\begin{array}{l}\text { A empresa adota práticas de proteção ambiental, pois preocupa- } \\
\text { se com o impacto ambiental da sua atividade. }\end{array}$ &, 567 \\
\hline
\end{tabular}

Quadro 7; Correlação entre inovação com as variáveis ambientais

Fonte: Elaborado pelos autores deste artigo 
As metalúrgicas do Vale dos Sinos mostram-se preocupadas no que tange ao impacto ambiental da sua atividade. Para mitigar essa inquietação, várias das empresas estudadas introduziram a preocupação com o meio ambiente na sua missão e valores, a fim engajar todos os setores nas causas ambientais. Contudo, as propostas para redução do impacto ambiental da sua atividade, novamente, voltam-se aos processos de fabricação. Esses processos dizem respeito à eliminação de produtos químicos e a emissões tóxicas e redução dos materiais das embalagens.

De forma geral, os principais resultados da análise de correlação sugerem que as metalúrgicas do Vale dos Sinos empenham-se de forma mais intensa na realização de inovação de processos, a fim de modificá-los ou substituí-los de modo a torná-los ambientalmente favoráveis, no sentido de reduzir o impacto ambiental da sua atividade. Tal constatação confirma as bases teóricas de Elefsiniotis e Warrham (2005), segundo a qual a gestão ambiental concerne à totalidade de ações organizacionais, de forma sistematizada para monitorar os impactos ambientais de suas atividades e gerenciar questões pertinentes à dimensão ambiental.

\section{Considerações Finais}

O objetivo geral desta pesquisa foi investigar como as organizações industriais do setor metalmecânico, localizadas na região do Vale do Rio dos Sinos, conciliam as atividades de inovação de produtos $e$ processos, com os princípios estruturantes da gestão ambiental. Com base nas evidências coletadas, constata-se que as companhias consideram apenas o atendimento aos dispositivos legais que exigem a mitigação dos impactos ambientais no processo de produção, em especial na redução da poluição e utilização de recursos menos tóxicos, o que não gera estímulo suficiente para o desenvolvimento de novos produtos.

Sendo assim, verificou-se que as organizações investigadas empenham-se de forma mais intensa na realização de inovação de processos, a fim de modificá-los ou substituí-los de modo a torná-los ambientalmente favoráveis, no sentido de reduzir o impacto ambiental da sua atividade. Tal fato ocorre em virtude de prevalecer a inovação de forma incremental nos produtos, isto é, as alterações feitas nos produtos se restringem à redução de custos e aperfeiçoamento do desempenho funcional.

Por conseguinte, percebe-se uma propensão de seguir as tendências do mercado ou até mesmo agregar atributos que atendam as exigências dos clientes, mas sem substituir alguma matéria-prima por outra menos poluidora, a fim de reduzir o impacto ambiental do novo produto. Assim, os dados advindos desta pesquisa comprovaram que, diante dos desafios ambientais, a inovação possibilita buscar soluções além dos problemas relacionados à escassez de recursos, oportunizando novas plataformas de negócios.

Ainda que esta pesquisa tenha atingido o objetivo proposto e que o rigor metodológico tenha sido perseguido, não se pode negar a existência de limitações. A primeira delas refere-se à utilização da escala tipo Likert, no instrumento de coleta de dados, uma vez que essa técnica apenas registra o nível de concordância ou discordância com relação a uma declaração dada. Como foi indagado apenas um colaborador de cada empresa, deve ser considerado o viés do respondente e o reducionismo da realidade, que é a característica da pesquisa do tipo survey.

Destaca-se ainda a limitação de ordem operacional, visto que o banco de dados utilizado na etapa quantitativa considera apenas o cadastro das empresas registradas no sistema da FIERGS. Como o cadastramento no sistema é realizado por iniciativa das empresas, acredita-se que muitas empresas podem não ter sido consideradas, para efeito do cálculo amostral. Entretanto, apesar dessa limitação, é possível afirmar que a referida base de dados é a melhor e mais completa do Estado.

Embora os dados da pesquisa não representem a totalidade das metalúrgicas do Vale do Rio dos Sinos, impossibilitando a generalização dos resultados, estes contribuem para a área do conhecimento. As limitações mencionadas, das análises dos resultados, acerca das práticas institucionalizadas em termos de aderência entre as práticas de inovar e de gestão ambiental, contribuem para a sugestão de novos estudos sobre o referido tema.

Sendo assim, os resultados obtidos indicam possibilidades para a continuidade da linha da pesquisa, a fim de investigar o motivo pelo qual as metalúrgicas não utilizam as linhas de financiamento público para estimular a inovação e acelerar o referido processo. 
Além disso, os dados advindos desta pesquisa comprovaram que, diante dos desafios ambientais, a inovação possibilita buscar soluções além dos problemas relacionados à escassez de recursos, oportunizando novas plataformas de negócios. Destarte, propõe-se, ainda, a realização de uma pesquisa que investigue o papel e a prática da inovação do modelo de negócio no contexto da sustentabilidade.

\section{REFERÊNCIAS}

ANDRADE, Rui Otávio Bernardes de; TACHIZAWA, Takeshy; CARVALHO, Ana Barreiros de. Gestão ambiental: enfoque estratégico aplicado ao desenvolvimento sustentável. 2. ed. São Paulo: Pearson Education do Brasil, 2002. 232 p.

ANPEI - Associação Nacional de Pesquisa, Desenvolvimento e Engenharia das Empresas Inovadoras. Pesquisa de Inovação. Rio de Janeiro: Instituto Brasileiro de Geografia e Estatística (IBGE), 2011. Disponível em: <http://www.pintec.ibge.gov.br/ downloads/pintec2011\%20publicacao\%20completa.pdf $>$. Acesso em: 9 out. 2016.

ARRUDA, Carlos Alberto et al. Cooperação e Inovações Ambientais: uma Análise de Empresas Brasileiras a Partir da PINTEC. In: ARRUDA, C.; CARVALHO, F. Inovações Ambientais: Políticas Públicas, Tecnologias e Oportunidade s de Negócio. Rio de Janeiro: Elsevier, 2014. p. 101-124. 328 p.

BANKUTI, S. M. S.; BANKUTI, F. I. A sincronia ou a sinergia ambiental estratégica: um estudo de práticas ambientais em empresa do setor alimentício. Revista de Gestão Social e Ambiental, São Paulo, v. 5, n. 2, p. 112-125, 2011.

BARBIERI, José Carlos. Gestão ambiental empresarial: conceitos, modelos e instrumentos. 3. ed. São Paulo: Saraiva, 2011. 358 p.

BEARD, Colin; REES, Stephen. Green teams and the management of environmental change in a UK county council. Environmental Management and Health, [S.l.], v. 11, n. 1, p.27-38, 2000.
BUNCHAFT, Guenia; KELLNER, Sheilah Rubino de O. Estatística sem mistérios. 4. ed. Petrópolis: Vozes, 2002. $227 \mathrm{p}$.

CAGNO, Enrico; TRUCCO, Paolo; TARDINI, Lorenzo. Cleaner production and profitability: an analysis of 134 industrial pollution prevention (P2) project reports. Journal of Cleaner Production, Holanda, v. 13, p. 593605, 2005.

COREDE - Conselho Regional de Desenvolvimento do Vale do Rio dos Sinos. [2014]. Disponível em: <http:// www.consultapopular.rs.gov.br/coredes.asp?cod_ corede $=19>$. Acesso em: 17 ago. 2014 .

CORTINA, Jose M. What is coefficient alpha? An examination of theory and applications. Journal of Applied Psychology, Washington, v. 78, p. 98-104, 1993.

DAVILA, Tony; EPSTEIN, Marc J.; SHELTON, Robert. As regras da inovação. Porto Alegre, RS: Bookman, 2007. $336 \mathrm{p}$.

DEL RíO, Pablo et al. Business strategies and capacities for eco-innovation. IE Business School Working Paper, [S.I.], EC8-124-I, 2011.

DIAS, Reinaldo. Gestão ambiental: responsabilidade social e sustentabilidade. 2. ed. São Paulo: Atlas, 2011. $220 \mathrm{p}$.

DONAIRE, Denis. Gestão Ambiental na Empresa. 2. ed. São Paulo, SP: Atlas, 2007. 169 p.

DYLLICK et al. Guia da Série de Normas ISO 14001: sistemas de gestão ambiental. Tradução de: Beate Frank, revisão: Ana Maria Bacca. Blumenau: Edifurb, 2000. 144 p.

ELEFSINIOTIS, Panagiotis; WAREHAM, David G. ISO 14000 environmental management standards: their relation to sustainability. Journal of Professional Issues in Engineering Education and Practice, [S.I.], v. 131, n. 3, p. 208-212, 2005.

FEE - Fundação de Economia e Estatística. Indicadores Econômicos 2013. [2014]. Disponível em: <http:// www.fee.tche.br/>. Acesso em: 26 maio 2014. 
FERNANDES, Jorge Monteiro. Gestão da tecnologia como parte da estratégia competitiva das empresas. Brasília, DF: IPDE, 2003. 274 p.

FIERGS - Federação das Indústrias do estado do Rio Grande do Sul. Indústria em Ação. Revista da Federação das Indústrias do Estado do Rio Grande do Sul, Rio Grande do Sul, ano 8. n. 90, maio de 2014.

FIERGS - Federação das Indústrias do estado do Rio Grande do Sul. Cadastro Industrial do Rio Grande do Sul. Porto Alegre: Unidade de Estudos Técnicos, Sistema FIERGS, 2013. CD-ROM.

FIERGS - Federação das Indústrias do estado do Rio Grande do Sul. Caderno Setorial do Rio Grande do Sul - Metalmecânico. Porto Alegre: Unidade de Estudos Técnicos, Sistema FIERGS, 2011.

FONSECA, Sérgio Azevedo; MARTINS, Paulo Sérgio. Gestão ambiental: uma súplica do planeta, um desafio para políticas públicas, incubadoras e pequenas empresas. Produção, São Paulo, v. 20, n. 4, p. 538-548, out.-dez. 2010.

GIOVINAZZO, Renata A. Modelo de Aplicação da Metodologia Delphi pela Internet: Vantagens e Ressalvas. Revista Administração On line, [on-line]. FECAP, São Paulo, v. 2, n. 2, abr.-jun. 2001. Disponível em: < http:// www.fecap.br/adm_online/ art22/renata.htm >. Acesso em: 27 jul. 2014.

GRAEL, Paulo Fernando Fuzer; OLIVEIRA, Otávio José de. Sistemas certificáveis de gestão ambiental e da qualidade: práticas para integração em empresas do setor moveleiro. Produção, São Paulo, v. 20, n. 1, p. 30-41, jan.-mar. 2010.

JABBOR, Charbel José Chiappetta. Contribuições da Gestão de Recursos Humanos para Evolução da Gestão Ambiental Empresarial: Survey e estudo de múltiplos casos. 2007. 198 f. Tese (Doutorado em Engenharia de Produção) - Programa de Pós-Graduação em Engenharia de Produção, Escola de Engenharia de São Carlos da Universidade de São Paulo, São Carlos, 2007.

KAYO, Eduardo Kazuo; SECURATO, Jose Roberto. Método Delphi: fundamentos, críticas e vieses. Caderno de Pesquisa em Administração, São Paulo, v. 1, n. 4, p. 51-61, abr. 1997.
KEMP, René; PEARSON, Peter. Final report MEI project about measuring eco-innovation. Maastricht: MEI (Measuring Eco-Innovation), 2007. 120 p. Disponível em: <http:/www.oecd.org/greengrowth/consumptioninnovation/43960830.pdf> Acesso: $1^{\circ}$ jul. 2014.

LARSON, Andrea L. Sustainability, Innovation, and Entrepreneurship. Saylor Foundation. [s.n.]: [S.l.], 2011. 312 p.

MANZINI, Ezio; VEZZOLI, Carlo. O desenvolvimento de produtos sustentáveis: os requisitos ambientais dos produtos industriais. São Paulo, SP: Editora da Universidade de São Paulo, 2002. 366 p.

MATTOS, João Roberto Loureiro de; GUIMARÃES, Leonam dos Santos. Gestão da tecnologia e inovação: uma abordagem prática. 2. ed. São Paulo, SP: Saraiva, 2013. 433 p.

MTE - MINISTÉRIO DO TRABALHO E DO EMPREGO. Relação Anual de Informações Sociais (RAIS). Disponível em: <http://portal.mte.gov.br/rais/> . Acesso em: 26 maio 2014.

MORT, J. Nature, value and pursuit of reliable corporate knowledge. Journal of Knowledge Management, [S.l.], v. 5, n. 3, p. 222-230, 2001.

MURILLO-LUNA, Josefina L.; GARCÉS-AYERBE, Concepción; RIVERA-TORRES, Pilar. Why do patterns of environmental response differ? A stakeholders' pressure approach. Strategic Management Journal, [S.I.], v. 29, n. 11 , p. 1.225-1.240. 2008.

NASCIMENTO, Luis Felipe. The environmental quality in companies of the agricultural, manufacturing and service sectors in south of Brazil. In: THE 7TH EUROPEAN ROUNDTABLE ON CLEANER PRODUCTION, Lund, Sweden, 2-4 May. 2001. Anais... Lund, Sweden, 2-4 May. 2001.

NIELSEN, Per H.; WENZEL, H. Integration of environmental aspects in product development: a stepwise procedure based on qualitative life cycle assessment. Journal of Cleaner Production, [S.l.], v. 10, n. 3, p. 247-57, Jun. 2002.

O'BRIEN, Meghan et al. The Eco-Innovation Gap: An economic opportunity for business. Eco-Innovation Observatory. Funded by the European Commission, DG Environment, Brussels. 2012. 73 p. 
OCDE - Organização para Cooperação e

Desenvolvimento Econômico. Manual de Oslo: Diretrizes para Coleta e Interpretação de Dados sobre Inovação. 3. ed. Rio de Janeiro: FINEP, 2005, Disponível em: <http:// www.mct.gov.br/index.php/content/view/4639.html>. Acesso em: 15 mar. 2012.

OLIVEIRA, Otávio José de; SERRA, José Roberto. Benefícios e dificuldades da gestão ambiental com base na ISO 14001 em empresas industriais de São Paulo. Produção, [S.l.], v. 20, n. 3, p. 429-438. jul.-set. 2010.

PERIN, Marcelo Gattermann. A Relação entre orientação para mercado, aprendizagem organizacional e performance. 2001. 194 f. Tese (Doutorado em Administração) - Programa de Pósgraduação em Administração de Empresas, Universidade Federal do Rio Grande do Sul, Porto Alegre, 2001.

PORTER, Michael E. Vantagem Competitiva: criando e sustentando um desempenho superior. 35. reimp. Rio de Janeiro: Elsevier, 1989. 512 p.

PORTER, Michael E; LINDE, Claas Van der. Green and competitive: ending the stalemate. Harvard Business Review, Massachusetts, v. 73, n. 5, p. 120-134, Set.-Out. 1995.

SAMPAIO, Cláudio Hoffmann. Relação entre orientação para mercado e performance empresarial em empresas de varejo de vestuário do Brasil. 2000. 234 f. Tese (Doutorado em Administração) - Programa de Pós-graduação em Administração de Empresas, Universidade Federal do Rio Grande do Sul, Porto Alegre, 2000.

SANCHES, Carmen Silva. Gestão ambiental proativa.

Revista de Administração de Empresas, [S.l.], v. 40, n. 1, p. 76-87, jan.-mar. 2000.

\section{SCHUMPETER, Joseph Alois. Teoria do}

desenvolvimento econômico: uma investigação sobre lucros, capital, crédito, juro e o ciclo econômico. São Paulo: Abril Cultural, 1982. 169 p.
SINMETAL - Sindicato das Indústrias Metalúrgicas, Mecânicas e de Material Elétrico e Eletrônico do Estado do Rio Grande do Sul. [2014]. Disponível em: <www. sinmetal.com.br>. Acesso em: 26 maio 2014.

SELLITTO, Miguel et al, Luciana Paulo. Environmental performance assessment of a provider of logistical services in an industrial supply chain. Theoretical Foundations of Chemical Engineering, [S.l.], v. 46, n. 6, p. 691-703, Nov. 2012.

SOUZA, Renato Santos de. Evolução e condicionantes da gestão ambiental na empresa. Revista Eletrônica de Administração, [S.l.], v. 8, n. 6, p. 1-22, nov.-dez. 2002.

STRAETE, Egil. Innovation and changing 'worlds of production': case-studies of Norwegian dairies. European Urban and Regional Studies, [S.I.], v. 11, n. 3, p. 227241, jul. 2004.

TACHIZAWA, Takeshy; ANDRADE, Rui Otávio Bernardes de. Gestão socioambiental: estratégias na nova era da sustentabilidade. 2. ed. Rio de Janeiro: Elsevier, 2012. $265 \mathrm{p}$.

TIDD, Joe; BESSANT, John. Inovação e empreendedorismo. 5. ed. Porto Alegre: Bookman, 2015. 512 p.

TOMS, Steve. Eco-logical. Financial Management, London, FMAI. Jan. 2001.

WITT, Ulrich. The crisis behind the crisis. Environmental Innovation and Societal Transitions. [S.1.], v. 6, p. 120-122. Mar. 2013.

WRIGHT, James T. C.; JOHNSON, Bruce B.; BIAZZI, Jorge L. O uso da técnica Delphi na elaboração de cenários. São Paulo, Petrobras, 1991. 31p. 


\section{Apêndice A - Questionário da Pesquisa}

Esta pesquisa tem por objetivo investigar como as organizações industriais do setor metalmecânico, localizadas na região do Vale do Rio dos Sinos, conciliam as atividades de inovação de produtos e processos, com os princípios estruturantes da gestão ambiental.

\section{Perfil da empresa e entrevistado:}

1. Cargo do Entrevistado:

2. Tempo na Função:

3. $\mathrm{N}^{\circ}$ de funcionários:

| | Até 19 | | De 20 a 99 | | De 100 a 499 | | Acima de 500

4. Localização da Empresa:

5. Tempo no mercado:

\section{Questões:}

O questionário está dividido em duas etapas. A primeira etapa aborda sua opinião sobre a dimensão das questões ambientais na empresa em que atuas. Na etapa seguinte, você deverá avaliar questões relacionadas a gestão da inovação e desenvolvimento de produtos.

As afirmativas devem ser avaliadas conforme sua percepção quanto mediante marcação de "X" nas colunas à direita da afirmação. Os números equivalem as seguintes afirmativas:

1 - Discordo totalmente;

2 - Discordo parcialmente;

3 - Não concordo nem discordo;

4 - Concordo parcialmente;

5 - Concordo totalmente;

6 - Sem condições de opinar.

\begin{tabular}{|c|c|c|c|c|c|c|c|}
\hline & DiMENSÃo DAS QUESTÕES AMBIENTAIS & 1 & 2 & 3 & 4 & 5 & 6 \\
\hline 1 & A empresa possui um setor de gestão ambiental estruturado. & & & & & & \\
\hline 2 & A dimensão ambiental está presente na estratégia empresarial. & & & & & & \\
\hline 3 & A preocupação com o meio ambiente está expressa na missão e valores da companhia. & & & & & & \\
\hline 4 & Existe envolvimento de todos os setores da empresa na busca pela qualidade ambiental. & & & & & & \\
\hline 5 & A gestão ambiental é tarefa de todos os setores da empresa. & & & & & & \\
\hline 6 & Os setores interagem entre si para a tomada de decisões em questões ambientais. & & & & & & \\
\hline 7 & A empresa exige dos fornecedores iniciativas de gestão ambiental. & & & & & & \\
\hline 8 & $\begin{array}{c}\text { A empresa busca opções de negócios em função das características } \\
\text { ecológicas de produtos, processos ou serviços. }\end{array}$ & & & & & & \\
\hline 9 & $\begin{array}{l}\text { A empresa preocupa-se em modificar ou substituir os processos } \\
\text { de modo a torná-los ambientalmente favoráveis. }\end{array}$ & & & & & & \\
\hline 10 & $\begin{array}{l}\text { A empresa preocupa-se em modificar ou substituir produtos } \\
\text { de modo a torná-los ambientalmente favoráveis. }\end{array}$ & & & & & & \\
\hline 11 & Existe preocupação em reduzir os materiais de embalagem. & & & & & & \\
\hline
\end{tabular}




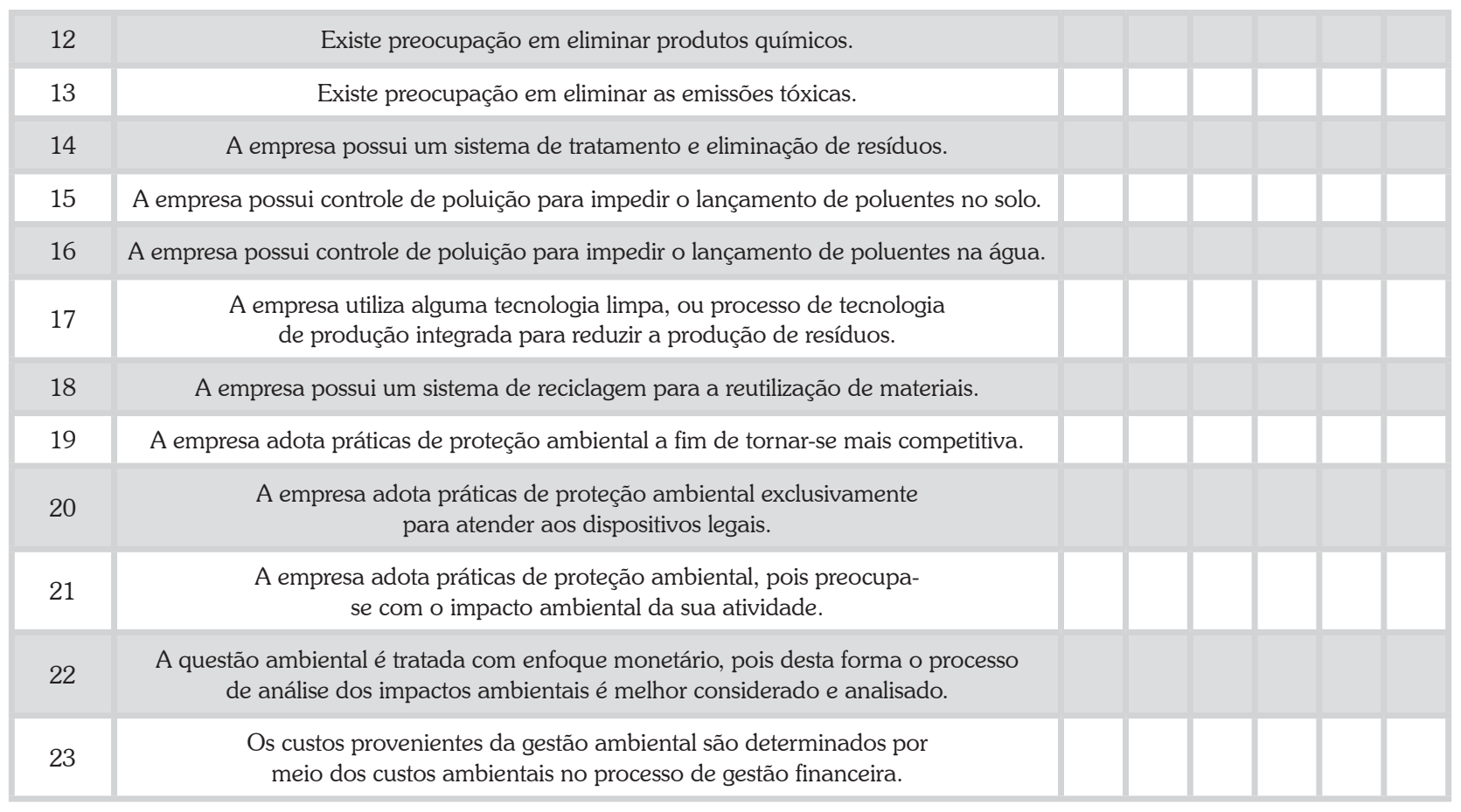

\begin{tabular}{|c|c|c|c|c|c|c|c|}
\hline & IDENTIFICANDO A INOVAÇÃO & 1 & 2 & 3 & 4 & 5 & 6 \\
\hline 1 & A empresa possui um setor de Pesquisa \& Desenvolvimento formalmente estabelecido. & & & & & & \\
\hline 2 & O foco em inovação consta na visão, missão, objetivos e estratégia da organização. & & & & & & \\
\hline 3 & $\begin{array}{l}\text { As propostas de mudanças em processos organizacionais ocorrem, na } \\
\text { maioria das vezes, por iniciativa dos ocupantes de cargos de direção. }\end{array}$ & & & & & & \\
\hline 4 & $\begin{array}{l}\text { As propostas de mudanças em processos organizacionais ocorrem, } \\
\text { na maioria das vezes, por iniciativa de consultores externos. }\end{array}$ & & & & & & \\
\hline 5 & $\begin{array}{l}\text { Ser reconhecida como uma organização que investe em } \\
\text { inovação de produtos e processos é importante. }\end{array}$ & & & & & & \\
\hline 6 & $\begin{array}{l}\text { Todos os produtos e processos da organização estão sendo constantemente } \\
\text { revisados, buscando sua melhoria e adequação à exigência de clientes. }\end{array}$ & & & & & & \\
\hline 7 & $\begin{array}{l}\text { Todos os produtos e processos da organização são constantemente revisados, } \\
\text { buscando melhor adequação as boas práticas de gestão ambiental. }\end{array}$ & & & & & & \\
\hline 8 & O foco central da inovação são os produtos. & & & & & & \\
\hline 9 & O foco central da inovação são os processos. & & & & & & \\
\hline 10 & As práticas de inovação devem contribuir para maior eficiência operacional. & & & & & & \\
\hline 11 & $\begin{array}{l}\text { A inovação depende do investimento em renovação do } \\
\text { parque fabril - máquinas e equipamentos. }\end{array}$ & & & & & & \\
\hline 12 & $\begin{array}{l}\text { Todo tipo de mudanças de produtos está sujeita a } \\
\text { aprovação prévia da direção da empresa. }\end{array}$ & & & & & & \\
\hline 13 & $\begin{array}{l}\text { Todo tipo de mudanças de processos está sujeita a } \\
\text { aprovação prévia da direção da empresa. }\end{array}$ & & & & & & \\
\hline 14 & As alterações de produtos são registradas em sistema interno. & & & & & & \\
\hline 15 & As melhorias de produtos são compartilhadas com os colaboradores. & & & & & & \\
\hline 16 & As melhorias de processos são compartilhadas com os colaboradores. & & & & & & \\
\hline
\end{tabular}




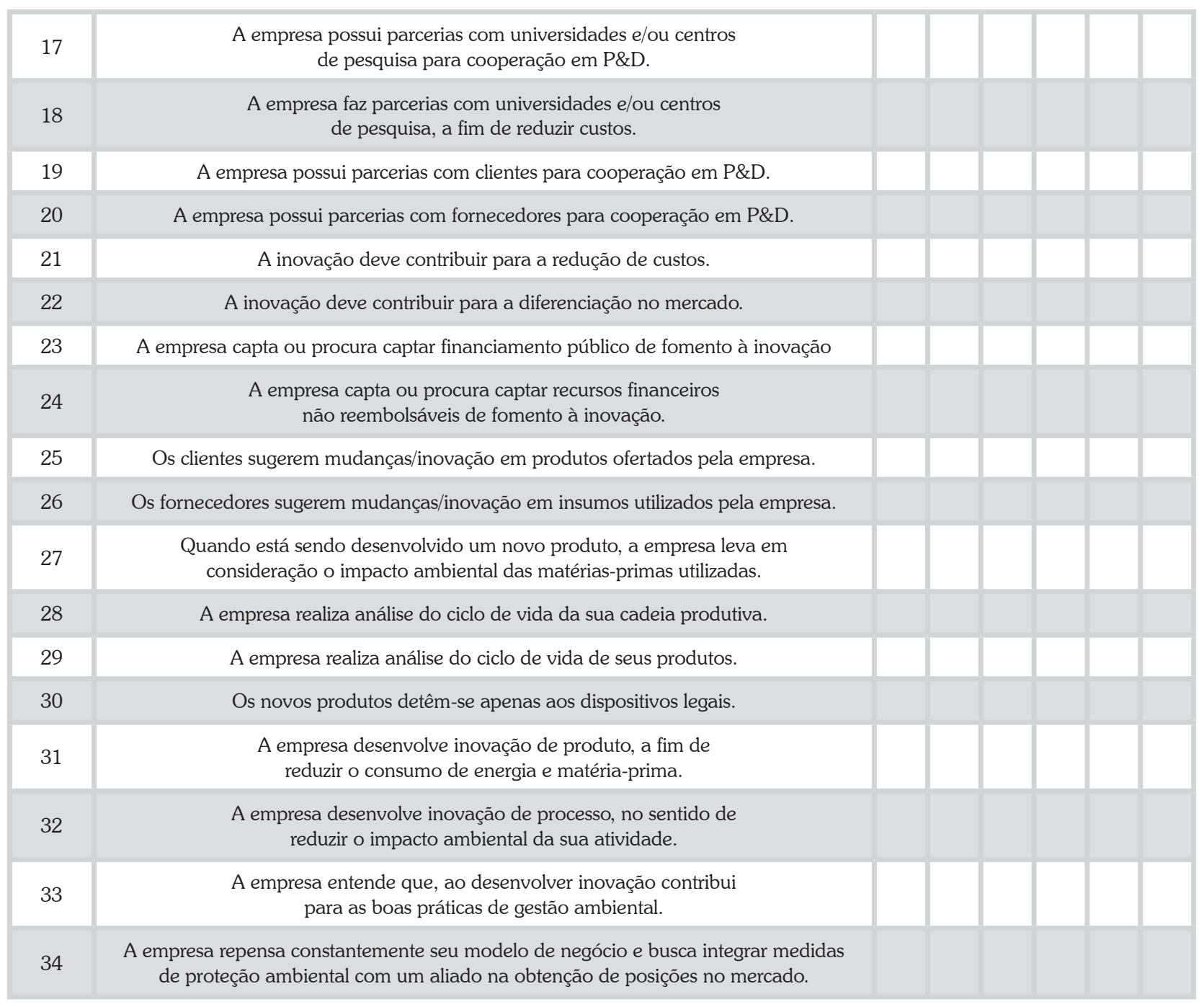

